\title{
Bio-Orthogonal Polymer Coatings for Co-Presentation of Biomolecules
}

\author{
Xiaopei Deng, Thomas W. Eyster, Yaseen Elkasabi, Joerg Lahann*
}

Controlled presentation of biomolecules on synthetic substrates is an important aspect for biomaterials development. If the immobilization of multiple biomolecules is required, highly efficient orthogonal surface chemistries are needed to ensure the precision of the immobilization. In this communication, chemical vapor deposition (CVD) copolymerization is used to fabricate polymer coatings with controlled ratio of alkyne and pentafluorophenyl ester (Pfp-ester) groups. Cyclic argine-glycine-aspartic acid (cRGD) adhesion peptide and epidermal growth factor (EGF) are immobilized through alkyne-azide cycloaddtion ("click" chemistry) and active ester-amine reaction, respectively. Cell studies with human umbilical vein endothelial cells (HUVEC) and A431 cell lines demonstrate the biological activity of the coimmobilized biomolecules.

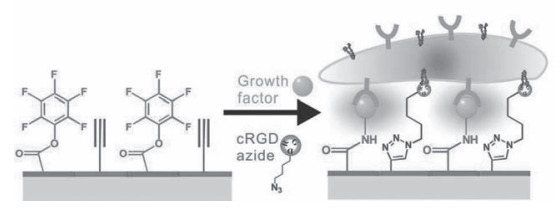

\section{Introduction}

The fate of cells cultured in a synthetic environment is, at least in part, governed by interactions with biomolecules on the substrate surface. ${ }^{[1]}$ The latter act as recognition sites that can induce and mitigate vital cellular functions such as adhesion, migration, and differentiation. ${ }^{[1 b]}$ Potential

X. Deng

Macromolecular Science and Engineering,

University of Michigan,

Ann Arbor, MI 48109, USA

T. W. Eyster

Chemical Engineering,

University of Michigan,

Ann Arbor, MI 48109, USA

Y. Elkasabi

Chemical Engineering,

University of Michigan, Ann Arbor, MI 48109, USA

Prof. Dr. J. Lahann

Departments of Chemical Engineering, Materials Science and Engineering, Macromolecular Science and Engineering and Biomedical Engineering, University of Michigan, Ann Arbor, MI 48109, USA; Institute of Functional Interfaces, Karlsruhe Institute of Technology, Hermann-von-

Helmholtz-Platz 1, 76344 Eggenstein-Leopoldshafen, Germany

E-mail: lahann@umich.edu applications include modification of implants ${ }^{[2]}$ such as stents, pacemakers, or grafts; use of polymer substrates for in vitro cell culture; ${ }^{[3]}$ or design of bioanalytical tools such as microarrays for protein, DNA, or polysaccharide detection. ${ }^{[4]}$ Because of the central role that cell-protein interactions play in biology, advanced applications in medicine and biotechnology require precise presentation of signaling molecules on the substrate surfaces. This revelation fueled a wide range of research activities focused on the controlled presentation of biomolecules on synthetic substrates. Initial work has included physisorption of proteins on substrate surfaces and covalent attachment using a number of nonspecific crosslinking reactions. ${ }^{[5]}$ More recent activities have taken advantage of novel immobilization concepts, such as click chemistry, to achieve controlled orientation of biomolecules on surfaces. ${ }^{[6]}$ The high specificity of click reactions may potentially provide an additional advantage: the possibility of presenting a combination of multiple biomolecules on the same surface using orthogonal chemical reactions, that is, reactions that do not show cross-reactivity toward their biological target molecules. ${ }^{[7]}$

Previously, we have developed chemical vapor deposition (CVD) polymerization technology to coat a range of functionalized poly- $p$-xylylenes on a variety of substrates. ${ }^{[8]}$ These reactive coatings provide different functional groups on different coatings that were used for 
immobilization of biomolecules such as peptides, proteins, and DNA. ${ }^{[2 a, 8 a, 9]}$ Moreover, it has been established that CVD copolymerization of [2.2]paracyclophanes containing different functional groups can be realized. This produces multipotent polymer coatings, which can be used for simultaneous presentation of multiple molecules in controlled ratios. ${ }^{[7 b]}$

With a number of specific chemical reactions in hand, ${ }^{[10]}$ the focus of bio-

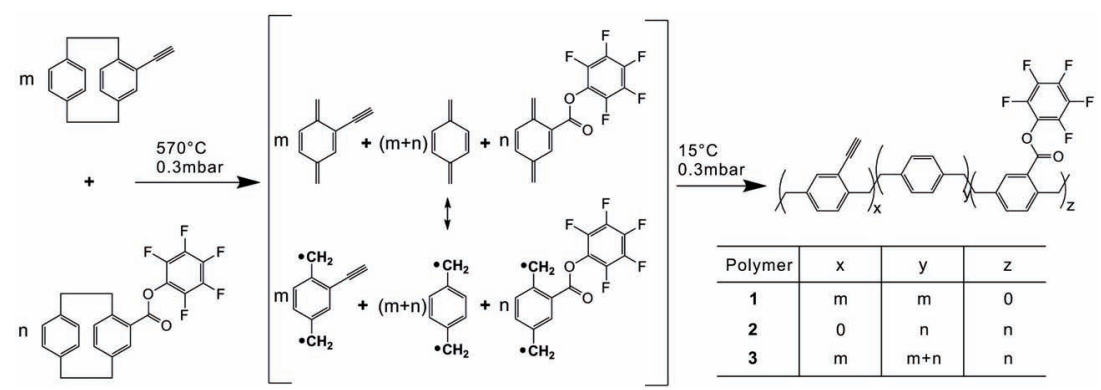

Scheme 1. CVD copolymerization of [2.2]paracyclophanes with pentafluorophenyl ester and alkyne groups; $\mathrm{m}=\mathrm{n}$ for the copolymer $\mathbf{3}$ discussed in this paper. medical engineers is now shifting from model systems to technology platforms that are equally applicable to a wide range of different substrate materials. Copper-catalyzed azide-alkyne 1,3-dipolar cycloaddition is one of the bio-orthogonal reactions, as defined by Sletten and Bertozzi. ${ }^{[7 a]}$ The reaction is also known as one of the "click" reactions, ${ }^{[11]}$ which are characterized by high reaction rate and selectivity. The azide-alkyne 1,3-dipolar cycloaddition has been used in a wide variety of applications, such as bioconjugation, drug design, organic synthesis, and polymer design. ${ }^{[12]}$ Pentafluorophenyl ester (Pfp-ester) groups are active esters commonly used in peptide synthesis, organic synthesis, polymer chemistry, and surface chemistry. ${ }^{[13]}$ Pentafluorophenyl ester groups can rapidly react with amines to form amide bond with no side reactions under mild conditions thus suitable for one-step immobilizations of proteins onto surface. ${ }^{[13 c]}$

Vapor-based coatings provide an attractive solution to major requirements associated with biomolecule immobilization applications, as they can result in ultrathin, conformal coatings that de facto decouple the surface properties from the underlying bulk material. ${ }^{[14]}$ In this paper, we design a multifunctional coating for simultaneous click reaction and active ester chemistry to achieve co-presentation of epidermal growth factor (EGF) and cyclic argine-glycine-aspartic acid (cRDG) adhesion peptides. Cell responses on the surface immobilized with two different biomolecules were then tested. (Scheme shown in Figure 2a) Our approach builds on recent progress with CVD co-polymerization, to develop multifunctional coatings that (1) can present two different biomolecules, that is, cyclic RGD peptide (cRGD) and epidermal growth factor (EGF); (2) offer orthogonal immobilization pathways; and (3) are applicable to a wide range of different substrate materials.

\section{Experimental Section}

\subsection{Materials}

All materials were purchased from Sigma-Aldrich and used without further purification unless otherwise indicated.

\subsection{CVD Co-polymerization}

The synthesis of the two precursors used in this study, 4pentafluorophenyl ester[2.2]paracyclophane and 4-ethynyl[2.2] paracyclophane was described elsewhere. ${ }^{[8 a, 15]}$ CVD co-polymerization was performed using 1:1 molar mixtures of the two precursors as shown in Scheme 1. The precursors sublimated under 0.3 mbar at temperatures above $100{ }^{\circ} \mathrm{C}$ and were transferred in a stream of argon carrier gas $(20 \mathrm{sccm})$ to the pyrolysis zone $\left(560{ }^{\circ} \mathrm{C}\right)$. Following pyrolysis, the diradicals were transferred into the deposition chamber, with the chamber wall temperature adjusted to $120^{\circ} \mathrm{C}$ and substrates cooled to $15^{\circ} \mathrm{C}$ to optimize the deposition. Moreover, rotation of the substrates ensured uniform film thickness.

\subsection{Surface Characterization}

IR spectroscopy was performed on a Nicolet 6700 spectrometer with the MCT-A detector and the grazing angle accessory (Smart SAGA) at a grazing angle of $80^{\circ}$. The coatings for IR characterization were all controlled at 50-60 nm. XPS data were recorded on an Axis Ultra X-ray photoelectron spectrometer (Kratos Analyticals, UK) equipped with a monochromatized AlK $\alpha$ X-ray source (takeoff angle $90^{\circ}$ ). All spectra were calibrated with respect to the non-functionalized aliphatic carbon with a binding energy of $285.0 \mathrm{eV}$. Thicknesses were measured by Imaging Spectroscopic Ellipsometer (Accurion, Nanofilm EP EP $^{3} \mathrm{SE}$ ). Ellipsometric parameters were fitted using Cauchy model. The imaging lateral resolution is $\approx 2 \mu \mathrm{m}$ for the $10 \times$ objective.

\subsection{Immobilization of EGF}

The procedure of immobilization of epidermal growth factor (EGF) and adhesion peptide is shown in Figure 2a. Microcontact printing $(\mu \mathrm{CP})$ was used in this study to confirm each immobilization step. PDMS stamps were created as described elsewhere. ${ }^{[16]}$ Stamps were oxidized for 20 min using UV-ozone cleaner before use. The stamps inked with EGF solution ( $10 \mu \mathrm{g} \mathrm{mL}^{-1}$ in PBS) were kept in contact with the sample surface for $10 \mathrm{~min}$. After stamp removal, the patterned samples were thoroughly washed with PBS. The immobilization reactions in solution without using $\mu \mathrm{CP}$ were the same as described above. The substrates immobilized with EGF were incubated with an anti-EGF antibody (a mouse IgG antibody) diluted in PBS containing $0.1 \%(\mathrm{w} / \mathrm{v})$ bovine albumin

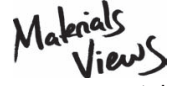

www.MaterialsViews.com 


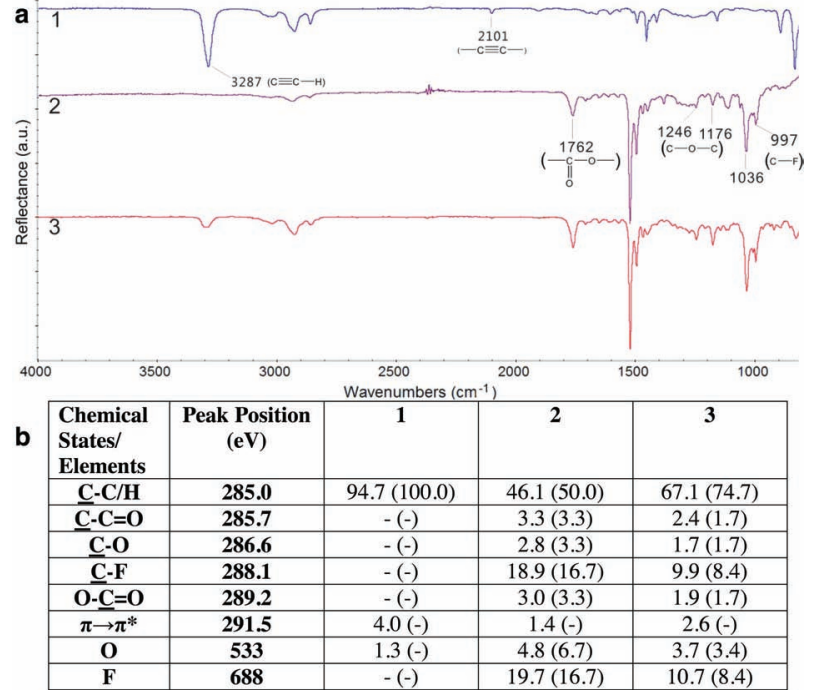

Figure 1. (a) Fourier transform infrared (FTIR) spectra for polymer $\mathbf{1}, \mathbf{2}$, and $\mathbf{3}$ and (b): chemical composition in atom\% shown as experimental value (calculated value in the bracket) determined by XPS; Experimental values of $\mathrm{O}$ and $\mathrm{F}$ atom ratios [\%] were obtained from survey results and other experimental values are from high resolution $C$ is spectra peak fitting calculated based on a equimolar distribution of starting materials. functional groups, which can covalently bind to different molecules using bio-orthogonal reaction pathways. The copolymer to be developed in this study is poly[(4-ethynyl$p$-xylylene)-co-(4-pentafluorophenyl ester-p-xylylene)-co(p-xylylene)] (3). Poly[(4-ethynyl-p-xylylene)-co-(p-xylylene)] (1) and poly[(4-pentafluorophenyl ester- $p$-xylylene)-co-( $p$ xylylene)] (2), which only have one of the two functional groups (either alkyne or pentafluorophenyl ester), are shown in Scheme 1 and Figure 1 for comparison. The Fourier transform infrared (FTIR) spectrum of copolymer 3 shown in Figure 1 reveals characteristic bands of alkyne groups (3287 and $2101 \mathrm{~cm}^{-1}$ ) and pentafluorophenyl ester groups (1762, 1523 , and 1250-990 $\mathrm{cm}^{-1}$ ). In addition, no sign of crossreactions between functional groups were observed during CVD polymerization. Next, the polymer films were analyzed by X-ray photoelectron spectroscopy (XPS), which has routinely been used to confirm the chemical composition of the outermost $10 \mathrm{~nm}$ of polymer films. The experimental values shown in Figure 1 are in good agreement with the calculated surface composition, which was obtained according to the chemical formula of the starting materials assuming stoichiometric conversion into the polymer. Detailed XPS analysis revealed and Tween $20(0.02 \%(\mathrm{v} / \mathrm{v}))\left(10 \mu \mathrm{g} \mathrm{mL} \mathrm{L}^{-1}\right)$ for $1 \mathrm{~h}$. After washing with the PBS/BSA/Tween buffer, the samples were incubated in the PBS/BSA/Tween buffer containing FITC conjugated antimouse IgG $\left(10 \mu \mathrm{g} \mathrm{mL} \mathrm{m}^{-1}\right)$ for $1 \mathrm{~h}$. The stained samples were then washed with $\mathrm{PBS}$, rinsed with distilled water, and observed under a fluorescence microscope (Olympus BX-51, Japan).

\subsection{Immobilization of the CRGD Peptide}

cRGD peptide with an azide end group (cyclo(azidoK-RGDf), Kinexus, Canada) was dissolved in an aqueous solution of sodium ascorbate $\left(50 \mathrm{mg} \mathrm{mL}^{-1}\right)$ and copper(II) sulfate $\left(0.1 \times 10^{-3} \mathrm{M}\right)$. The peptide concentration was $50 \mu \mathrm{g} \mathrm{mL}^{-1}$. The stamp inked with the peptide azide solution was then kept in contact with the sample surface for $4 \mathrm{~h}$, followed by stamp removal and repeated washing with PBS and deionized water. The condition was the same for reaction in solution without using $\mu \mathrm{CP}$.

\section{Results and Discussion}

To achieve controlled immobilization of multiple biomolecules, we first had to develop a polymer coating with multiple

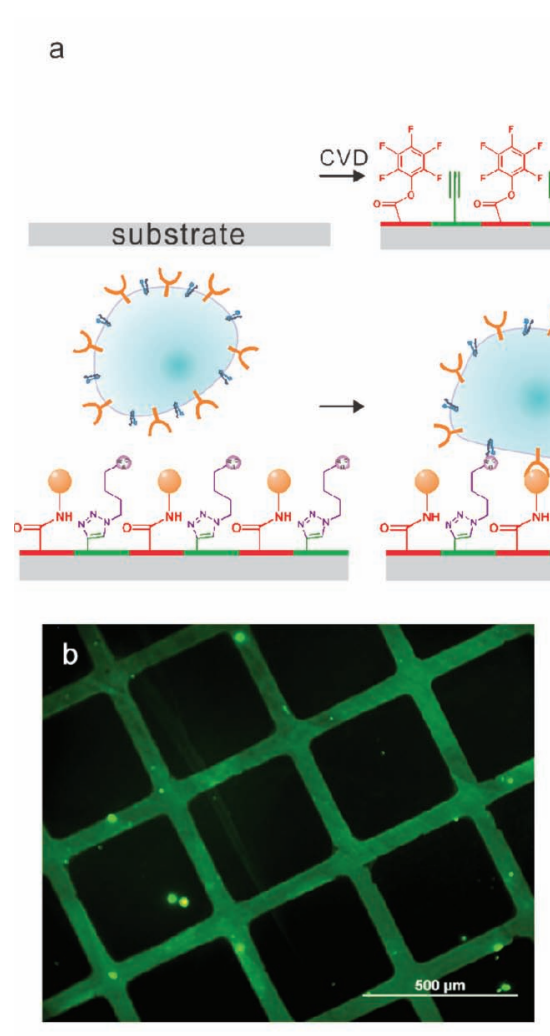

Growth factor CRGD azide 8
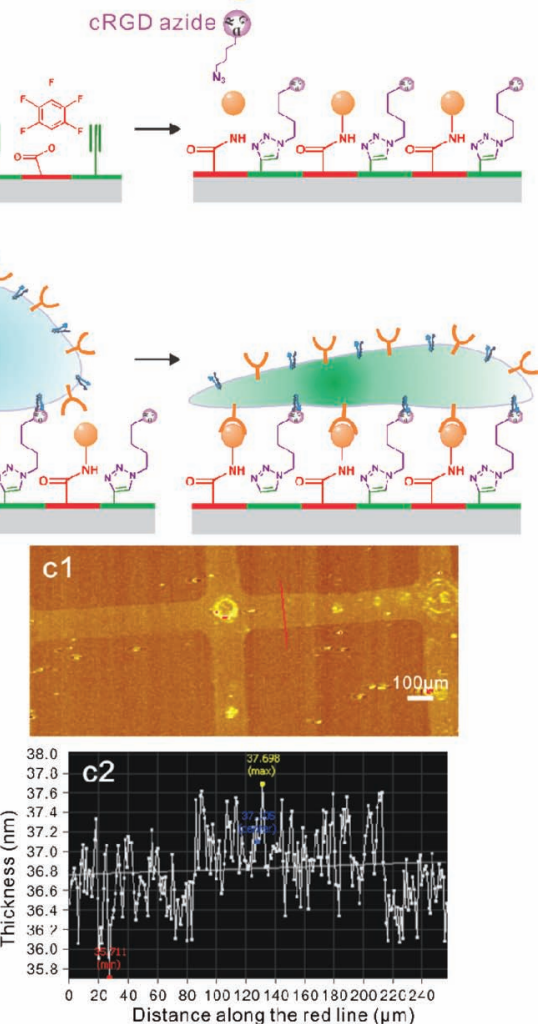

Figure 2. (a) Scheme for CVD copolymerization, biomolecules immobilization, and potential cell responses. (b) Fluorescence micrograph of epidermal growth factor (EGF) immobilized in patterned area after $\mu \mathrm{CP}$ and immunostaining. (c1) Imaging ellipsometry thickness map of cRGD peptide pattern. (c2) Thickness profile representing thickness difference along the red line shown in (c1). 
concentrations of $\mathrm{F}$ and $\mathrm{C}-\mathrm{F}$ in the copolymer $\mathbf{3}$ to be approximately half of polymer 2, which only carries pentafluorophenyl ester groups on the surface. It shows that by feeding 1:1 molar ratio of the different precursors, approximately 1:1 ratio of each functional group was observed on the surface.

To confirm that the simultaneous surface conjugation of both the peptide and growth factor was feasible, microcontact printing was used to create patterned substrates of protein or peptide. Areas not modified during microcontact printing were used as an internal reference. The cRGD peptide was immobilized using click chemistry (i.e., Huisgen's [1,3]dipolar cycloaddition catalyzed by $\mathrm{Cu}^{+}$ions), and EGF was tethered covalently by reaction with the highly reactive Pfp-ester group to form an amide bond with the terminal primary amine. Immunostaining was used to visualize the immobilized EGF. The polymer 3 coated substrates functionalized with EGF at the patterned area were incubated in anti-EGF antibody (primary antibody) solution, washed and then immersed in the solution of FITC conjugated antimouse IgG (secondary antibody). Figure $2 \mathrm{~b}$ shows that after immunostaining of the entire surface, only the area with EGF showed fluorescence. This suggests that the active ester chemistry for growth factor immobilization (Figure 2a) was successful. The cRGD peptide immobilization was characterized by imaging ellipsometry. Figure 2c1 and c2 show that the thickness of the area patterned with cRGD peptide via click chemistry was approximately $0.5 \mathrm{~nm}$ higher than the unpatterned area, which confirmed that the CRGD peptide was immobilized on the surface of polymer 3 .

We then evaluated the immobilization of cRGD via click reaction and assessed peptide activity in the presence of immobilized growth factor. The RGD tripeptide is a well-studied cell adhesion motif present in many proteins, but perhaps most prominently in extracellular matrix (ECM) molecules, such as fibronectin and vitronectin (among others). ${ }^{[17]}$ RGD (and other small peptide adhesion molecules) have been widely explored for use in tissue engineering and presents several advantages over full-length proteins such as fibronectin, including issues such as enzymatic denaturation and overall combined).
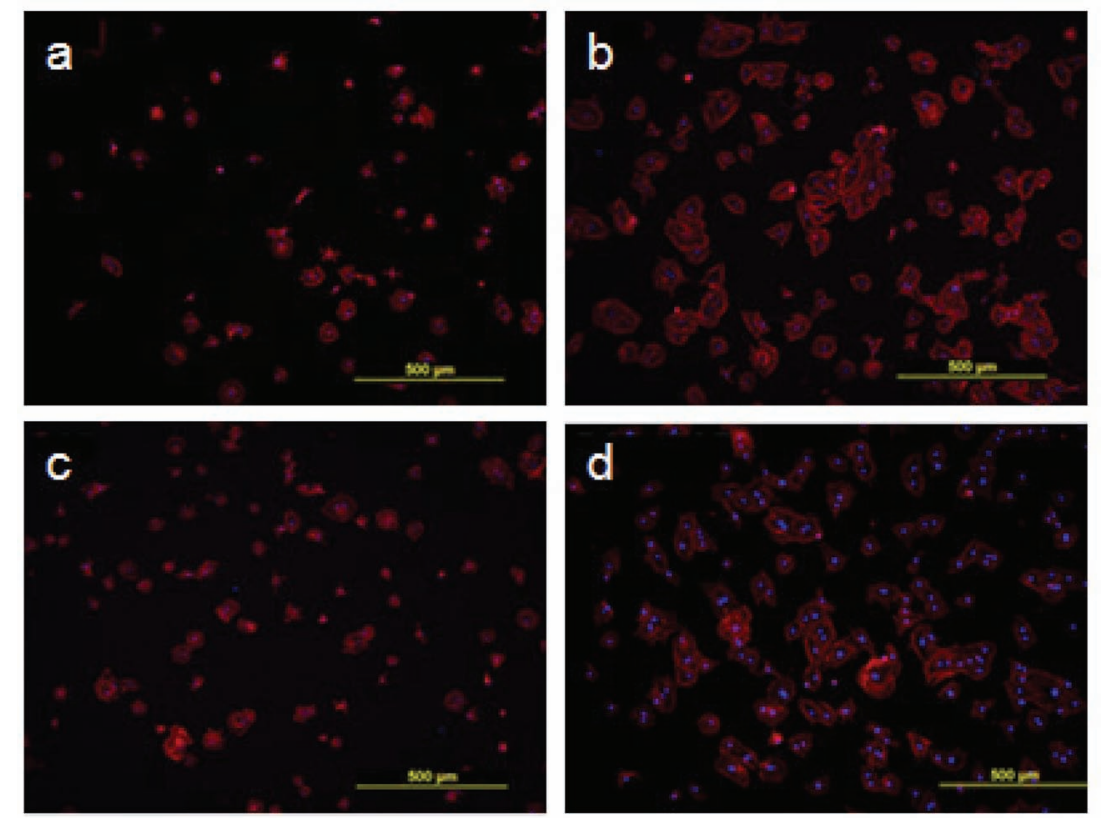

\section{e Normalized HUVEC Area: Alkyne-Pfp ester copolymer}

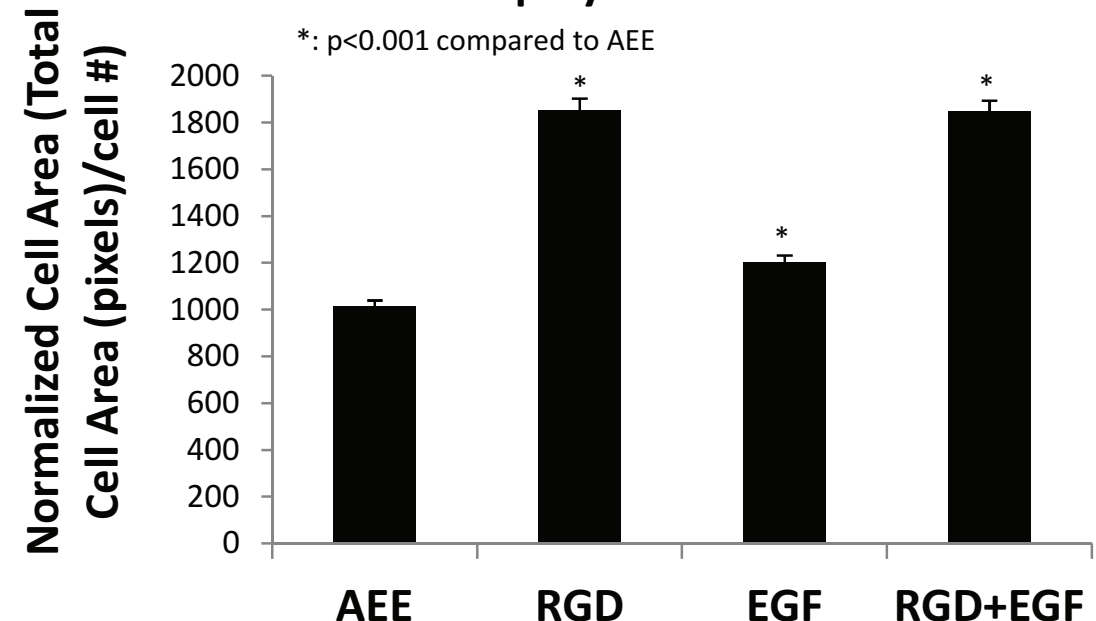

Figure 3. Fluorescence micrographs of HUVEC line seeded onto modified surfaces of polymer 3 after $4 \mathrm{~h}$ incubation. The surfaces were tethered with: (a) AEE, (b) CRGDonly, (c) EGF-only, (d) CRGD + EGF. (e) Quantification of spreading by ImageJ (three trials

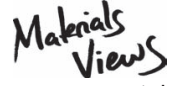

www.MaterialsViews.com 
enhanced by the presence of CRGD. The cell area on the surface with both CRGD and EGF was approximately the same as the one with only CRGD. The surface immobilized only with EGF only had a slight increase in cell area. The observance that EGF did not have any obvious effect on HUVECs is consistent with other studies showing the absence of EGFR expression in normal HUVECs. ${ }^{[20]}$

Tethering growth factors has gained more interest from the scientific community within the last three decades. ${ }^{[21]}$ Studies showed that the immobilized growth factors, compared to the soluble ones, had higher mitogenic effect, longer-term signal transduction and were resistant to endocytosis, degradation and diffusion. ${ }^{[22]}$ In order to verify that the immobilized EGF still have biological activity,
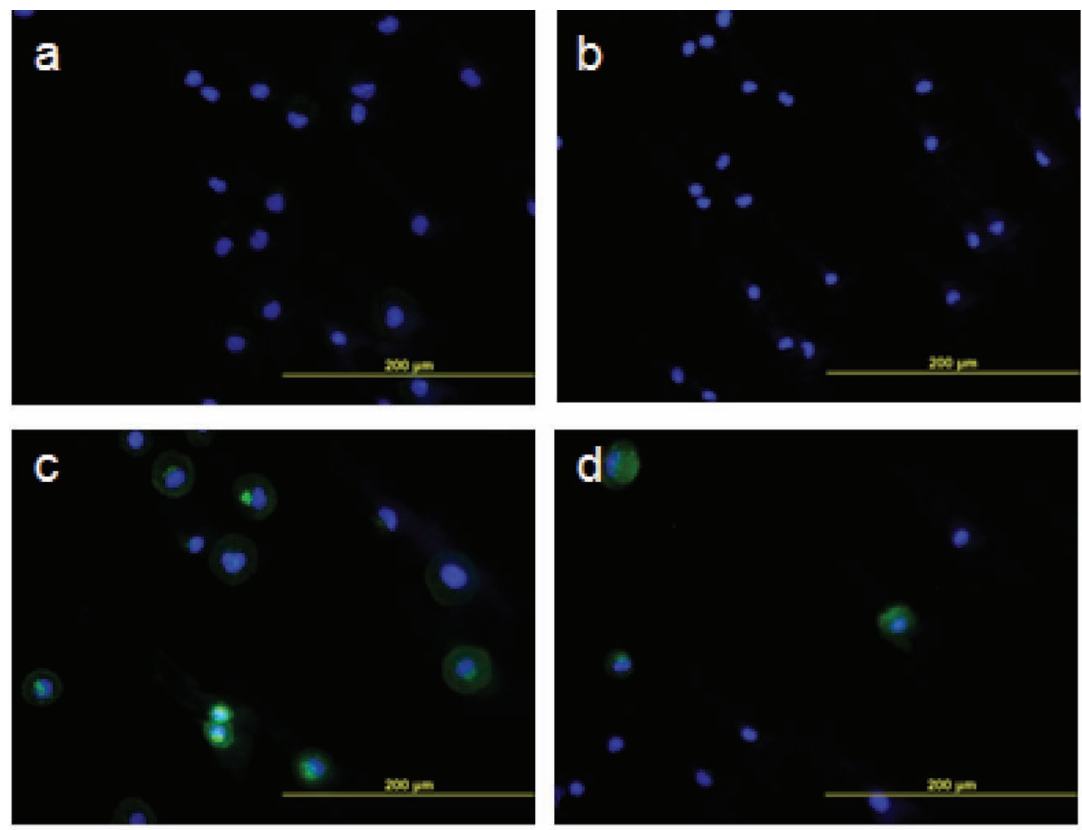

\section{e \\ Quantification of A431 pEGFR}

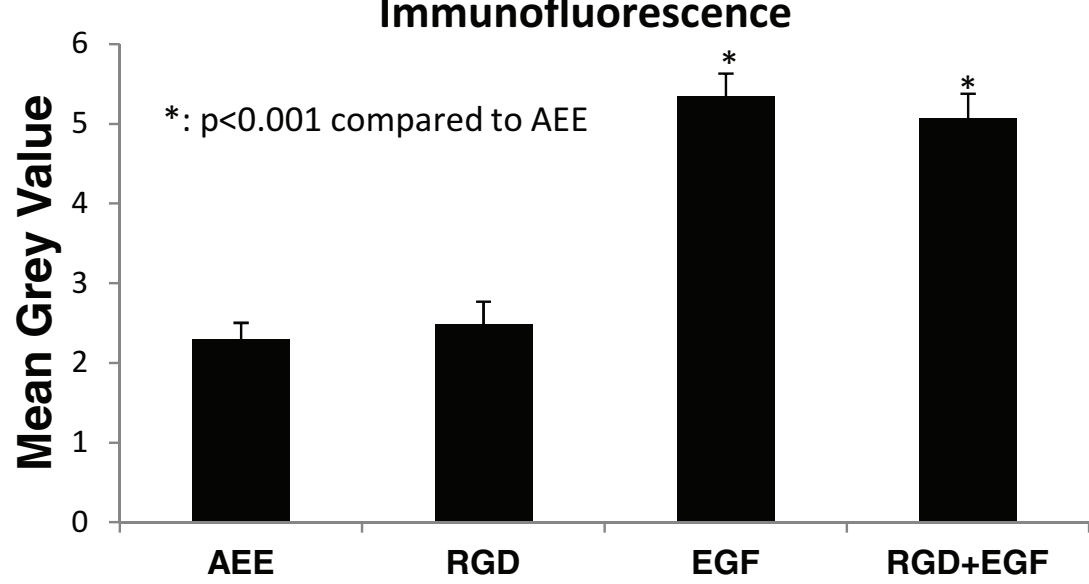

Figure 4. Immunofluorescence of phosphorylated EGFR in A431 cells cultured on CVDcoated surfaces with tethered (a) AEE, (b) CRGD, (c) EGF, and (D) CRGD+EGF. (e) Quantification of pEGFR immunofluorescence (three trials combined). we investigated our modified surfaces' ability to induce phosphorylation of EGFR (pEGFR), the receptor of EGF. The A431 line is a human epidermal carcinoma and a wellcharacterized positive control for EGFR activity. ${ }^{[23]}$ A431 cells overexpress EGFR roughly 10-50-fold over many other cell lines, and thus are an ideal cell type for examining the bioactivity of tethered EGF. ${ }^{[2]}$ Surfaces with tethered EGF successfully induce phosphorylation of EGFR in serumstarved A431 cells, as observed using immunofluorescence (Figure 4). This shows that the immobilized EGF on polymer 3 maintained its biological activity. Surfaces exhibiting both the adhesion factor CRGD and EGF show statistically similar $(p<0.001)$ pEGFR phosphorylation compared to those exhibiting EGF alone, demonstrating that multiple biofactors do not affect this particular growth factor's ability to interact with its receptor. We next examined A431 EGFR phosphorylation in response to soluble EGF and compared it to tethered EGF (Figure S1, Supporting Information). Various literature indicate that $\mathrm{A} 431$ respond to EGF with $\mathrm{EC}_{50}$ values of $12.1 \mathrm{ng} \mathrm{\textrm {mL } ^ { - 1 }}$ and $20 \mathrm{ng} \mathrm{mL}^{-1}$, respectively. ${ }^{[25]}$ From four independent trials, an average $\mathrm{EC}_{50}$ value was $14.8 \mathrm{ng} \mathrm{mL}^{-1} \pm 3.02 \mathrm{ng} \mathrm{mL}^{-1}$ (standard error), well matching the reported literature values previously cited. In all four trials, EGFR phosphorylation of tethered EGF as measured by quantification of immunofluorescence was either statistically equivalent to or higher $(p<0.05)$ than the highest concentration of soluble EGF tested (1000 ng mL ${ }^{-1}$ ), demonstrating the potency of tethered EGF.

\section{Conclusion}

The herein developed immobilization scheme has been successfully developed to immobilize a peptide and a growth factor. In independent experiments, we have further been able to demonstrate biological activity of the respective factor in the presence of the second biomolecules. Future work include validating this technique for other growth factors and chemokines, tethering patterns of different factors to induce topology-specific differentiation of human mesenchymal stem cells, and using two-source CVD to create precise gradients of factors for induction of differential morphogenesis in various epithelial lines. 


\section{Supporting Information}

Supporting Information is available from the Wiley Online Library or from the author.

Acknowledgements: X. D. and T. W. E. contributed equally to this work. The authors gratefully acknowledge support from Army Research Office (ARO) Grant W911NF-11-1-0251, NIH tissue engineering and regeneration training grant and NSF CAREER grant DMR-0449462.

Received: November 30, 2011; Revised: December 19, 2011; Published online: February 21, 2012; DOI: 10.1002/marc.201100819

Keywords: biomaterials; biomolecules; coatings; immobilization; surface engineering

[1] a) B. D. Ratner, S. J. Bryant, Annu. Rev. Biomed. Eng. 2004, 6, 41; b) D. G. Castner, B. D. Ratner, Surf. Sci. 2002, 500, 28.

[2] a) J. Lahann, D. Klee, W. Pluester, H. Hoecker, Biomaterials 2001, 22, 817; b) M. Morra, Expert Rev. Med. Devices 2007, 4 , 361; c) P. Hanefeld, U. Westedt, R. Wombacher, T. Kissel, A. Schaper, J. H. Wendorff, A. Greiner, Biomacromolecules 2006, 7, 2086.

[3] a) Y. Zhang, X. P. Deng, E. L. Scheller, T. G. Kwon, J. Lahann, R. T. Franceschi, P. H. Krebsbach, Biomaterials 2010, 31, 3231; b) H. Hatakeyama, A. Kikuchi, M. Yamato, T. Okano, Biomaterials 2007, 28, 3632.

[4] a) S. J. Oh, B. J. Hong, K. Y. Choi, J. W. Park, Omics 2006, 10, 327; b) D. N. Wang, S. Y. Liu, B. J. Trummer, C. Deng, A. L. Wang, Nat. Biotechnol. 2002, 20, 275.

[5] A. S. Hoffman, J. A. Hubbell, in Biomaterials Science, Second Edition: An Introduction to Materials in Medicine, 2nd edition (Eds: B. D. Ratner, A. S. Hoffman, F. J. Schoen, J. E. Lemons), Elsevier Academic Press, San Diego, CA 2004, p. 225.

[6] S. Dedola, D. L. Hughes, S. A. Nepogodiev, M. Rejzek, R. A. Field, Carbohydr. Res. 2010, 345, 1123.

[7] a) E. M. Sletten, C. R. Bertozzi, Angew. Chem. Int. Ed. 2009, 48 , 6974; b) Y. Elkasabi, H. Y. Chen, J. Lahann, Adv. Mater. 2006, 18, 1521.

[8] a) J. Lahann, M. Balcells, T. Rodon, J. Lee, I. S. Choi, K. F. Jensen, R. Langer, Langmuir 2002, 18, 3632; b) H. Y. Chen, M. Hirtz,
X. P. Deng, T. Laue, H. Fuchs, J. Lahann, J. Am. Chem. Soc. 2011, 132, 18023.

[9] S. Thevenet, H. Y. Chen, J. Lahann, F. Stellacci, Adv. Mater. 2007, 19, 4333.

[10] H. Y. Chen, J. Lahann, Langmuir 2011, 27, 34.

[11] H. C. Kolb, M. G. Finn, K. B. Sharpless, Angew. Chem. Int. Ed. 2001, 40, 2004.

[12] H. Nandivada, X. W. Jiang, J. Lahann, Adv. Mater. 2007, 19, 2197.

[13] a) F. Albericio, Biopolymers 2000, 55, 123; b) H. Zhao, T. R. Burke, Tetrahedron 1997, 53, 4219; c) P. Theato, J. Polym. Sci. A Polym. Chem. 2008, 46, 6677; d) J. Lahann, I. S. Choi, J. Lee, K. F. Jenson, R. Langer, Angew. Chem. Int. Ed. 2001, 40, 3166.

[14] M. E. Alf, A. Asatekin, M. C. Barr, S. H. Baxamusa, H. Chelawat, G. Ozaydin-Ince, C. D. Petruczok, R. Sreenivasan, W. E. Tenhaeff, N. J. Trujillo, S. Vaddiraju, J. Xu, K. K. Gleason, Adv. Mater. 2010, 22, 1993.

[15] H. Nandivada, H. Y. Chen, L. Bondarenko, J. Lahann, Angew. Chem. Int. Ed. 2006, 45, 3360.

[16] H. Y. Chen, J. Lahann, Adv. Mater. 2007, 19, 3801.

[17] E. Ruoslahti, M. D. Pierschbacher, Science 1987, 238, 491.

[18] a) K. Shakesheff, S. Cannizzaro, R. Langer, J. Biomater. Sci., Polym. Ed. 1998, 9, 507; b) M. Kantlehner, P. Schaffner, D. Finsinger, J. Meyer, A. Jonczyk, B. Diefenbach, B. Nies, G. Holzemann, S. L. Goodman, H. Kessler, ChemBioChem 2000, 1, 107.

[19] R. Haubner, R. Gratias, B. Diefenbach, S. L. Goodman, A. Jonczyk, H. Kessler, J. Am. Chem. Soc. 1996, 118, 7461.

[20] a) K. Al-Nedawi, B. Meehan, R. S. Kerbel, A. C. Allison, J. Rak, Proc. Natl. Acad. Sci. USA 2009, 106, 3794; b) D. N. Amin, K. Hida, D. R. Bielenberg, M. Klagsbrun, Cancer Res. 2006, 66, 2173.

[21] B. Liberelle, C. Boucher, J. K. Chen, M. Jolicoeur, Y. Durocher, G. De Crescenzo, Bioconjugate Chem. 2010, 21, 2257.

[22] a) P. R. Kuhl, L. G. Griffith-Cima, Nat. Med. 1996, 2, 1022; b) Y. Ito, Soft Matter 2008, 4, 46.

[23] J. Rubin Grandis, M. F. Melhem, W. E. Gooding, R. Day, V. A. Holst, M. M. Wagener, S. D. Drenning, D. J. Tweardy, J. Natl. Cancer Inst. 1998, 90, 824.

[24] A. Ullrich, L. Coussens, J. S. Hayflick, T. J. Dull, A. Gray, A. W. Tam, J. Lee, Y. Yarden, T. A. Libermann, J. Schlessinger, J. Downward, E. L. V. Mayes, N. Whittle, M. D. Waterfield, P. H. Seeburg, Nature 1984, 309, 418.

[25] a) E. J. Westover, D. F. Covey, H. L. Brockman, R. E. Brown, L. J. Pike, J. Biol. Chem. 2003, 278, 51125; b) D. Waddleton, C. Ramachandran, O. Wang, Anal. Biochem. 2002, 309, 150.

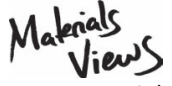

